\title{
Evaluation of the Effects of Coarse Aggregate Sizes on Concrete Quality
}

\author{
Lawrence E. Obi
}

\begin{abstract}
This work was necessitated by the observations made at construction sites where artisans and craftsmen were left alone in concrete production. It was discovered that they used inadequate quantity and size of coarse aggregates due to difficulty associated in the mixing as if the coarse aggregates were not needed in concrete production. The research has established that the coarse aggregates and their sizes play critical roles in the development of adequate strength in concrete. It was observed that with proper mixing, the slump test results did not witness shear or collapse type of slump rather there were true slump in all cases of the test. The workability decreased with slight differences when the coarse aggregate size was increased. The increase in the coarse aggregates yielded appreciable increase in the compressive strength. It can therefore be inferred that the quality of concrete in terms of strength can be enhanced through an increase in the coarse aggregate size when proper mix ratio, batching, mixing, transporting, placing and finishing are employed in concrete productions.
\end{abstract}

Index Terms-Aggregates; Concrete; Compressive Strength; Workability.

\section{INTRODUCTION}

Concrete is a composite material whose major constituents include cement, fine aggregates, coarse aggregates and water. Admixtures can be added to cement, aggregates and water to achieve a particular purpose. The constituent components of plain concrete have significant roles which they are expected to play in their service conditions with the intention of achieving desired characteristics and quality. While the cement is serving as a binder, the fine aggregates help in reducing the occurrence of voids, the coarse aggregates impact adequate strength to the concrete and the water activates the binding capability of the cement. The qualities of concrete include inter alia workability, durability and strength. These qualities can best be achieved when the various components of concrete are in the right proportion and this leads to the concrete mix design ratio. The relative quantities of cement, aggregates and water in concrete control the properties of concrete in the wet state as well as in the hardened state [1],[2].

Concrete serves many purposes and its intended purpose determines the proportions of the cement, aggregates, water and possibly some admixtures. Plain concrete does not possess reinforcement such as steel but when reinforcement is integrated into its composition, it is described as reinforced concrete. Ordinarily, plain concrete is not subjected to imposed load but reinforced concrete is meant to carry load. Concrete quality also varies generally

Published on October 9, 2017.

L. E. Obi is with the Civil Engineering Department, Imo State University, Owerri, Imo State, Nigeriaç (e-mail: engrlawobi@yahoo.com) according to its method of preparation and the mix ratio. Concrete prepared by a vibrator has a higher quality than concrete prepared manually.

It is well a known fact that coarse aggregates play essential part and role in concrete. Coarse aggregates typically occupy over one third of the volume of concrete. There are evidences that aggregate type is a factor in the strength of concrete. The role of coarse aggregate sizes in concrete is the concentration of this research. The interest in this study was borne out of the neglect in the application of coarse aggregates in concrete production among the local artisans and craftsmen in the construction industry [4],[5].

\section{A. Concrete}

Concrete as a composite material derives its quality from the component parts. Concrete can be classified as highstrength and normal strength concrete. Compressive strength is the most important attribute of concrete and it is on this basis that the classification of concrete was carried out. The major difference between high strength concrete and normal strength concrete lies on its compressive strength. Compressive strength is normally defined as the maximum resistance which a particular concrete can offer to an applied pressure. High strength concrete is normally called high performance concrete while normal strength concrete is known as normal performance concrete [3],[6].

According to American Concrete Institute, high strength concrete (high performance concrete) is a concrete whose compressive strength is greater than $41 \mathrm{MPa}$ (6000Psi). The high performance concrete is regarded as a superior product with increased modulus of elasticity, lower creep and drying, shrinkage, excellent freeze thaw resistance, low permeability and increased chemical resistance. High performance concrete is prescribed when reduced load is needed or when the architectural demand requires small support element for carrying load. When the cost of the high performance concrete is evaluated based on compressive strength, it can be observed that the cost of high performance concrete is more economical. High performance reinforced concrete is commonly recommended for high-rise buildings. It is an established fact that the structural inhomogeneity of concrete consisted of hard cement paste holding aggregates and with the interface zone created around and between the aggregates and the cement paste. The aggregate plays an essential role in the concrete in load transfer due to its sternness and strong characteristic [7],[8].

Concrete that is freshly mixed ready to be moulded or poured into is any formwork is called plastic or green concrete. The mix ratio of the cement, aggregates and water which form a concrete controls its properties in the wet state as well as in the hardened state. The water/cement ratio 
applied in concrete mix ratio is normally 0.38 . According to Shetty, use of water/cement ratio more than this will result to capillary cavities and less than this, leads to incomplete hydration and creates inadequate space in the system for the development of gel. However, there may be adjustments on this ratio due to surface moisture in the aggregates or as a result of the absorption characteristics of dry and porous aggregates. The actual water/cement ratio to be adopted at the site depends on the above described conditions.

\section{B. Concrete Production}

The manufacturing of concrete needs adequate care, skill and dexterity to ensure that the produced concrete has a high quality. Both poor and high quality concrete are made from the same ingredients and at times with the same component ratio but the difference between these is the production process. If meticulous care is not exercised and good rules are not followed, the resultant concrete is likely to be of poor quality. The various steps of concrete production include batching, mixing, transporting, placing, compacting, curing and finishing [1]-[3].

Batching is the measurement of materials for making concrete according to the designed mix ratio. There are two types of batching namely volume batching and weight batching. Volume batching is not considered ideal in the construction industry because of the flaws inherent in the measurement of volume of granular materials especially coarse aggregates. Weight batching is the proportioning of the component materials through weight measurement. Weight batching is more ideal and recommended for batching. Cement which is also used in batching is always rated in weight. In Nigeria, a bag of cement sold in the market weighs $50 \mathrm{~kg}$. Invariably, for good concrete, weight batching system should be adopted. The application of the weight batching system facilitates accuracy, flexibility and simplicity. Different weight batches are available. The type to be used depends on the magnitude and nature of the project. Large weight batching plants have automatic weighing equipment. The use of this automatic equipment for batching is one of a great sophistication and requires qualified and experienced engineers. Automatic batching plants are available both $\mathrm{n}$ small and large capacities.

Mixing is a process in concrete production that is very critical in its final quality. Thorough mixing of materials ensures compatibility, homogeneity and effective bondage of the materials involved in concrete production. Proper mixing ensures uniform colour and consistency. The two methods involved in mixing materials for concrete production are manual and machine mixing. Manual mixing is normally done by hand and is used for minor and insensitive projects. Mixing materials through this method is not desirable, and it is never thorough and efficient. Manual mixing does not allow the proper interaction of the cement, sand and coarse aggregates and most often it is difficult to execute. Manual mixing has produced poor concrete as artisans/craftsmen prefer to carry out the mixing with little or no coarse aggregates. Machine mixing of materials for concrete production is preferable. Machine mixing is carried out through a vibrator and it is not only efficient but also economical when the amount of concrete to be produced is large. The available and known mixers are the batch-mixers and continuous mixers. Batch-mixers produce concrete batch by batch with time interval but continuous mixers produce concrete continuously without stoppage until it is intentionally put off.

The trump card in the transportation of concrete is that the homogeneity attained during the time of mixing should be maintained while being transported to the final point of application. The common methods used in transporting concrete include mortar pan, head pan, wheel barrow, hand cart, crane-bucket-and-rope way, truck-mixer-and-dumper, belt conveyors, chute, skip and hoist, transit mixer, pumpand-pipe-line and helicopter.

It is not enough that concrete is correctly designed, batched, mixed and transported but it is of utmost importance that the concrete be correctly placed in a systematic manner to achieve optimal results. For instance, when placing concrete on a foundation bed as blinding, the bed must be properly cleaned of loose soil and if the foundation bed is rain-soaked, the water and the slush must be removed before placing the concrete. Apart from wet foundation beds, the bed should be watered to prevent the soil of the bed from collecting water from the concrete to be placed.

Compaction of green concrete is very vital as it helps to close voids that would have existed in the concrete structure. It helps the concrete withstand imposed load without fracture. Compaction is also applied to expel the entrapped air from concrete. If not expelled properly, the concrete loses strength considerably. Compaction can be achieved manually or mechanically through vibrators.

The gaining of strength by concrete is not an immediate process but the strength is achieved over a specified period of time. The process of exposing the concrete to water to enable it to attain a maximum strength over a considerable period of time is called curing. The exposure to water enables cement to keep undergoing the process of hydration which helps the entire concrete structure to gain more strength. Concrete finishing is necessary to enable concrete possess adequate aesthetic outlook.

\section{Aggregates}

Aggregates are normally considered as inert filler which accounts for $70-80 \%$ of the concrete volume and $70-85 \%$ of the weight of concrete. Although, aggregates are said to be inert filler, it is an indispensable component which defines the concrete's thermal and elastic properties and dimensional stability. Aggregates also give body to the concrete, reduce shrinkage and enhance its economy. Normal weight aggregates can be classified into two, namely; natural and artificial. The natural normal weight aggregates include sand, gravel, crushed rock such as granite, quartzite, basalt, sandstone while artificial aggregates include broken brick, air-cooled slag, sintered fly ash, and bloated clay.

Most gueous rocks make satisfactory concrete aggregates, because they are normally hard and dense. The igneous rock has massive structure, entirely crystalline or wholly glassy. The target maximum size of aggregates practicable to handle under a given condition in concrete has been limited to a maximum size of $80 \mathrm{~mm}$ for the purposes of convenience. Aggregates are classified on the basis of size 
as coarse and fine aggregates. Coarse aggregates are aggregates whose sizes are more than $4.75 \mathrm{~mm}$ (retained on a No. 4 sieve while fine aggregates are aggregates whose sizes are $4.75 \mathrm{~mm}$ or less. In terms of shape, aggregates can be classified as rounded, irregular, angular and flaky. At the standpoint of economy, rounded aggregates are preferable to angular aggregates. Aggregates wield enormous impact on concrete as it determines its strength, durability and structural capacity.

\section{Workability of Concrete}

Workability can be defined as the consistency, which indicates the measure of fluidity or the mobility of green concrete. A theoretical water/cement ratio is not enough to create an ideal situation necessary for the attainment of maximum strength by concrete. A complete compaction of concrete is an important parameter that contributes to maximum strength. Inadequate compaction will lead to air voids whose damaging effects on the strength of concrete and durability are equally more predominant than the presence of capillary cavities. For concrete to be adequately compacted, a higher water/cement than that calculated by theoretical consideration is needed. This means that the role of water is to lubricate the concrete to ensure that effective compaction is achieved within normal efforts [1],[5].

When a concrete possesses water adequate for lubrication without segregation the concrete is considered as being prone for easy compaction which finally produces an aesthetically finished concrete, such a concrete is said to be workable. This can only be achieved at a certain quantity of water. Workability is a parameter, a mix designer is required to specify in the mix design process, bearing in mind the type of work, distance of transportation, loss of slump, method of placing and any other parameter involved. Assumption of right workability with proper understanding backed by experience will make the concreting operation economical and durable. The factors which enable concrete to have more lubricating effect and also reduce internal friction for easy compaction are water content, mix proportion, size of aggregates, shape of aggregates, surface texture of aggregates, grading of aggregates, and use of admixtures. Workability is normally measured through the following tests viz slump test, compacting factor test, flow test, Kelly Ball test and Vee Bee Consistometer test. The slump test is the most commonly used method of measuring consistency of concrete.

\section{E. Concrete Strength}

The compressive strength is normally used as a qualitative measure for hardened concrete. This compressive strength is the most useful property of concrete. In structural engineering, concrete is applied primarily to resist compressive stresses. Concrete is good in resisting compressive forces but steel has the ability to resist tensile forces. The integration of steel in concrete (normally called reinforced concrete) is to produce a structural member that has the capacity to resist both tensile and compressive forces. The end product of the concrete mix design is to have a desired compressive strength that will meet the needs of the project. Practically, the strength of concrete is its resistance to rupture. When concrete fails under a compressive load, the failure is essentially a mixture of crushing and shear failure [3],[7].

The compressive strength of concrete is determined by testing cubes made in laboratory through crushing by the compressive testing machine. Concrete develops strength with continued hydration. The rate of gain of strength is faster at the beginning as the rate declines with age. Actually, concrete develops strength beyond twenty-eight days.

\section{MATERIALS AND METHOD}

The empirical method of research was used in this research. The methodical processes employed in this work were batching, mixing, transporting, placing, compacting, curing and destructive testing of the concrete cubes. The materials used in the research include ordinary Portland, cement, fine aggregates well drained river sand, coarse aggregates (crushed granites) and water

\section{A. Concrete Manufacturing}

A common mix ratio of 1:3:6 was employed in the batching of the materials. The weight batching method was used and the materials (cement, fine aggregates, coarse aggregates were mixed manually with cement/water ratio of 0.45. The mixed green concrete was meticulously transported and placed on a $150 \mathrm{~mm}$ x $150 \mathrm{~mm}$ x $150 \mathrm{~mm}$ mould. The placed concrete was compacted adequately to eliminate capillary cavities and voids. The sizes of coarse aggregates used in the manufacturing includes $12.5 \mathrm{~mm}$ (1 inch), $19.5 \mathrm{~mm}$ ( $3 / 4 \mathrm{inch}), 25 \mathrm{~mm}$ (1 inch) and' a mixture of $12.5 \mathrm{~mm} 19.5 \mathrm{~m}$ and $25 \mathrm{~mm}$. For each size of coarse aggregates used in the concrete production, 40 cubes were produced and this gave a total of 160 cubes of the concrete made with the various sizes of coarse aggregates. The concrete cubes produced with coarse aggregates sizes of $12.5 \mathrm{~mm}$. $19.5 \mathrm{~m}, 25 \mathrm{~m}$ and mixture of $12.5 \mathrm{~mm}, 19.5 \mathrm{~mm}$, $25 \mathrm{~mm}$ were properly labelled and marked.

\section{B. Slump Test}

Slump test is the most commonly used test to measure consistency of concrete. It is not good for very wet or very dry concrete. The equipment used for slump consists of a metallic mould in the form of a frustum of a cone and it is provided with suitable guides for vertical lifting. There is also a steel tamping rod which is used with the frustum. The mould is normally placed on a smooth horizontal rigid and non-absorbent surface. The mould is then in four layers and each layer is tamped evenly for twenty-five times with the rod. The mould is removed from the concrete immediately by raising it slowly and vertically. At this point the concrete subsides and the subsidence is referred to as slump of the concrete. The difference in level between the height of the mould and that of the subsided concrete is measured and this gave the measure of the slump. The three types of slump obtained in a slump test are true slump, shear slump and collapse and they are shown in Fig. 1. 
$\downarrow$

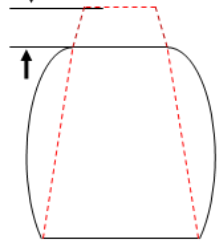

True Slump $\downarrow$

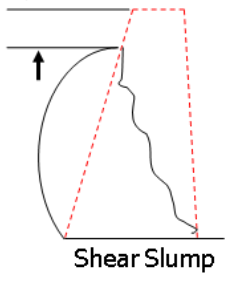

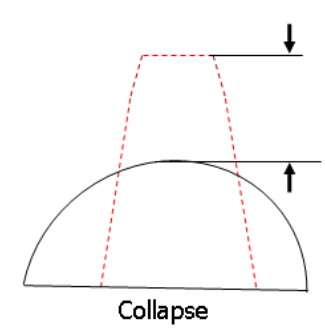

$\downarrow$

Fig. 1. Types of Slump

\section{Compressive Strength Test}

The produced 160 concrete cubes were cured in the water curing basin and subjected to crushing at an interval of 7 days, 14 days and 28 days of time. At the time of crushing, ten cured concrete cubes of each size of coarse aggregates were crushed at a given concrete age of 7 days, 14 days, 21 days and 28 days. This was achieved by placing the cast faces of the concrete cube to be in contact with the platens of the universal testing machine which was electrically operated. In accordance with BS 1881: part 116: 1983, the load on the cube was applied at a constant rate of stress equal to $0.26 \mathrm{pa} / \mathrm{sec}$. The force or load that resulted to failure of each cube was taken and used in calculating the compressive strength. The testing was done at the Civil Engineering Laboratory of Imo State University, Owerri.

\section{RESULTS AND ANALYSIS}

\section{A. Results}

The results of the slump test and compressive strength of concrete cubes produced with the various coarse aggregate sizes of $12.5 \mathrm{~mm}, 19.5 \mathrm{~mm}, 25 \mathrm{~mm}$ and the mix of $12.5 \mathrm{~mm}$, $19.5 \mathrm{~mm}, 25 \mathrm{~mm}$ for the curing ages of 7 days, 14 days, 21 days and 28 days were presented on Table I and II respectively.

TABLE I: RESULT FOR SLUMP TEST OF CONCRETE FROM VARIOUS AGGREGATE SIZES

\begin{tabular}{lccccc}
\hline \hline Sample & $\begin{array}{c}\text { Concrete } \\
\text { Mix } \\
\text { Ratio }\end{array}$ & $\begin{array}{c}\text { Coarse } \\
\text { Aggregate } \\
\text { Sizes }\end{array}$ & $\begin{array}{c}\text { Slump } \\
\text { Value } \\
(\mathbf{C m})\end{array}$ & Nature & Slump \\
\hline $\mathrm{X}$ & $1: 3: 6$ & $\mathbf{1 2 . 5 m m}$ & 6.4 & True & Slump \\
$\mathrm{Y}$ & $1: 3: 6$ & $19.5 \mathrm{~mm}$ & 8.2 & True & Slump \\
$\mathrm{Z}$ & $1: 3: 6$ & $25.0 \mathrm{~mm}$ & 100 & True & Slump \\
$\mathrm{W}$ & $1: 3: 6$ & Mix & 9.3 & True & Slump \\
\hline \hline
\end{tabular}

TABLE II: RESUlTS OF COMPRESSIVE STRENGTHS OF CONCRETE MADE FROM DIFFERENT COARSE AGGREGATES SIZES

\begin{tabular}{lcccccc}
\hline $\begin{array}{l}\text { Sample } \\
\text { Identification }\end{array}$ & $\begin{array}{c}\text { Concrete } \\
\text { Mix } \\
\text { Ratio }\end{array}$ & $\begin{array}{c}\text { Coarse } \\
\text { Aggregate } \\
\text { Sizes }\end{array}$ & \multicolumn{4}{c}{$\begin{array}{c}\text { Average Compressive } \\
\text { Strength (N/mm }\end{array}$} \\
& & & $\mathbf{7}$ & $\mathbf{1 4}$ & $\mathbf{2 1}$ & $\mathbf{2 8}$ \\
days & days & days & days \\
\hline X & $1: 3: 6$ & $12.5 \mathrm{~mm}$ & 18.5 & 20.5 & 19.0 & 23. \\
Y & $1: 3: 6$ & $19.5 \mathrm{~mm}$ & 20.0 & 21.6 & 23.2 & 23.5 \\
$\mathrm{Z}$ & $1: 3: 6$ & $25.0 \mathrm{~mm}$ & 22.5 & 31.7 & 35.7 & 39.2 \\
$\mathrm{~W}$ & $1: 3: 6$ & Mix & 30.0 & 30.4 & 31.3 & 35.4 \\
\hline \hline
\end{tabular}

\section{B. Result Analysis}

The properties of concrete considered in this research are mainly its compressive strength and workability. These two characteristics have much influence on the durability, consistency and the overall performance of concrete in its area of application. The slump test which was determined from green concrete did not measure all the factors responsible for workability nor was it always a representation of the placability of concrete. But it was used as a control test which gave the uniformity of concrete from batch to batch. The quality of concrete can be observed from its workability through the indication on the nature of slump. The three types of slumps observed in a slump test for a concrete include true slump, shear slump and collapse. Owing to the level of meticulousness exhibited in the concrete preparation, the concrete would be said to be properly prepared.

The observation made during the workability test revealed that the concrete made from the four different sizes of coarse aggregates yielded true slump. This showed a higher workability generally. On individual basis, the $12.5 \mathrm{~mm}$ coarse aggregate concrete showed more degree of workability as the test yielded the least slump value of $6.4 \mathrm{~cm}$. A low workability in concrete (higher slump value) shows that the concrete is of low quality and therefore such a concrete is susceptible to segregation. Segregation in concrete is an undesired property as it means the separation of the constituent parts of concrete. When a concrete exhibits the tendency for segregation, that concrete will be weak and its lacks of homogeneity will eventually induce unacceptable properties in the hardened concrete. With the results in Table I, it was indicated that the slump value tends to increase with increasing coarse aggregate size. Invariably, this suggested that the increase in coarse aggregate size may adversely affect workability if adequate precautions are not observed in the preparation of such a concrete.

The average values of the compressive strengths of concrete are illustrated on Table II. From the results as shown on the table, it was observed that the concrete prepared with the coarse aggregates $(12.5 \mathrm{~mm}, 19.5 \mathrm{~mm}$, $250 \mathrm{~mm}$ and mix) showed proportional increase in their compressive strength with increase in the age of the concrete. It can also be deciphered from the Table II that the concrete prepared with the coarse aggregate of size of $25.0 \mathrm{~mm}$ gained the highest compressive strength of 39.2 $\mathrm{N} / \mathrm{mm} 2$ and it was followed by the concrete made from the mix aggregates. This tends to suggest that with the proper batching process, the compressive strength of concrete may be considered to be proportional to the coarse aggregate size. When the appropriate batching process (weight batching) is employed large sized coarse aggregates can still create adequate surface area for the developments of gel bonds which contributes immensely to the compressive strength of concrete. Locally, this must have been the reason for employing large sized coarse aggregates at the foundation stage of most storeyed buildings.

The relationships existing between the coarse aggregate size and compressive strength and coarse aggregates and workability are shown on Fig. 2 and 3 respectively. 


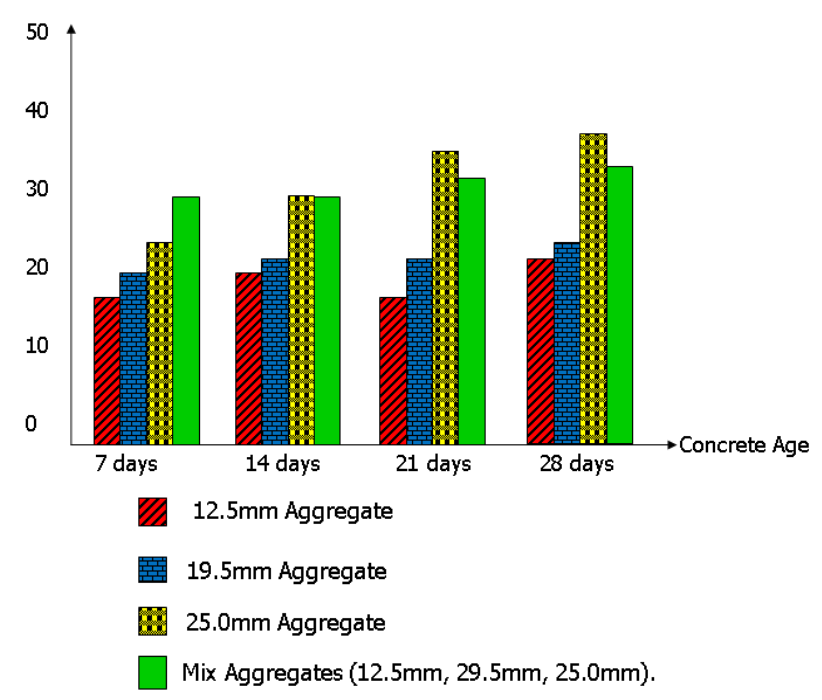

Fig. 2 Compression Test Results

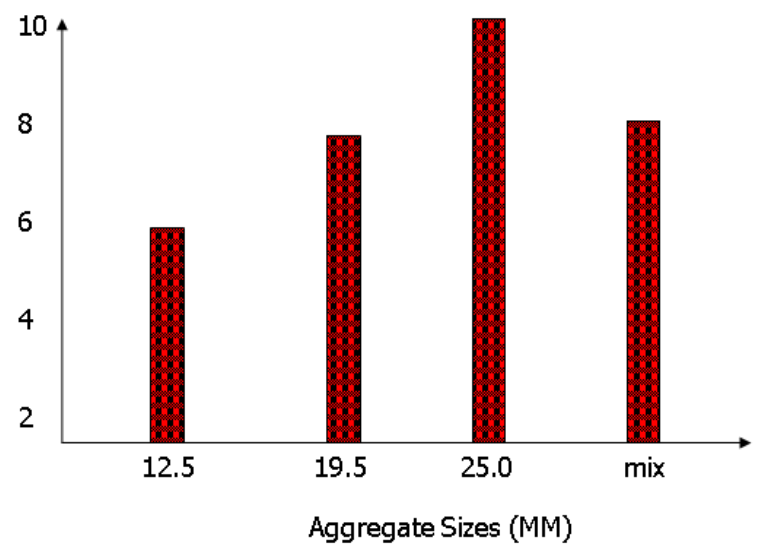

Fig. 3. Slump Test Results.

\section{CONCLUSION AND RECOMMENDATIONS}

\section{A. Conclusion}

Coarse aggregates are critical in the development of strength by concrete. The work has analysed the effects of the sizes of coarse aggregates in the compressive strength and workability. It was exposed that the durability and the ability of a concrete to serve its intended purposed were partly predicated on the coarse aggregate sizes. With the appropriate mix design ratio and good workmanship coarse aggregate sizes could enhance the compressive strength and workability of concrete.

In actual practice, artisans and craftsmen avoid coarse aggregates in the manual batching and mixing of materials for concrete manufacturing due to the difficulties associated in the mixing of coarse aggregates (especially the largesized coarse aggregates) with cement and fine aggregates. It has been often noticed that in some occasions they omit the coarse aggregates entirely or use little and inadequately sized coarse aggregates. The research work revealed that the various sizes of coarse aggregates hard positive and appreciative effect in the concrete quality.

\section{B. Recommendations}

With the results of this research, it is recommended that;

1. Coarse aggregates with the appropriate size must be used in the production of concrete in accordance with the specified concrete strength and workability.

2. Mix ratio design, batching and mixing of materials must be effectively monitored and supervised by professional engineers to ensure that the right quantity and sizes of materials are employed as this is a critical aspect of quality control.

3. The weight batching method is highly acceptable as against the current trend of volume batching.

4. Mixing of concrete materials should be by machines (batching plants) since most often manual mixing does not produce concrete with high workability.

\section{ACKNOWLEDGMENT}

My foremost appreciation goes to the staff of Civil Engineering Department of Imo State University, Owerri Nigeria especially the technologists used in all the laboratory work. I thank my beloved wife- Mrs Fidelia Nwanneka Law-Obi and all my children for their unquantifiable encouragement extended to me during the period of this research.

\section{REFERENCES}

[1] M.S. Shetty, Concrete Technology Theory and Practice, S. Chand \& Company Ltd., Ram Nagar, New Delhi, pp. 217-297, 1st Edition, 2009.

[2] L.E. Obi, "Empirical investigation of the effects of water quality on concrete compressive strength", international journal of constructive research in civil engineering, Volume 2, Issue 5, Pp. 30-35, 2016. www.arcjournals.org.

[3] L.E. Obi, "Investigation of the Adaptability of Quarry Dust as Fine Aggregate in Concrete Production", Journal of Science and Technology Research, vol. 6, No.1, pp. 64-71, 2013.

[4] K. Kozalija and D. Daniel, Report on Structural Engineering and Engineering Materials. SM Report No. 43, university of Kansas centre for research, Inc. Lawrence Kansas, 1997.

[5] P.J. Tumidajski and B. Gong, "Effect of coarse aggregate size on strength an workability of concrete". Canadian journal of civil engineering, Canada, Vol. 33, No. 2, 2006.

[6] N.A. Abd-Hamid and N.F. Abas, "A study on effects of size coarse aggregates in concrete". Journal Tecknologi, Universiti Technologi, Malaysia, Vol. 75, No. 5, 2015.

[7] A.M. Neville, Properties of Concrete 4th edition, with Longman, 1995 .

[8] H.K. Steven and C.P. William, Design and control of Concrete mixture, PCA, 1988.

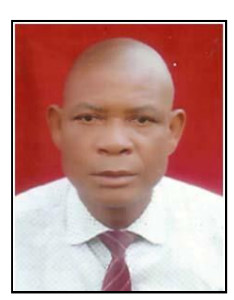

Engr. Dr. Obi Lawrence E.is a native of Ihioma in Orlu, Imo State Nigeria and he is a Senior Lecturer in the Department of Civil Engineering, Imo State University, Owerri. He holds a Ph.D in Civil Engineering from the renowned Federal University of Technology, Owerri, Imo State, Nigeria.

$\mathrm{He}$ is an experienced academic who has served as the Head of Civil Engineering Department and through his dint of hardwork and mental prowess facilitated the accreditation of his department by Council for the Regulation of Engineering in Nigeria and the Nigerian Universities Commission. He is a chartered engineer and belongs to many professional bodies which include Nigerian Society of Engineers, Nigerian Institution of Civil Engineers, Nigerian Institution of Water Resources Engineering, Nigerian Renewable Energy Society, etc. He is a Fellow of the Institute of the Industrial Administration of Nigeria.

Engr. Dr.L.E. Obi has published extensively both in national and reputable international journals. He has earned such awards as the best H.O.D. Award for Civil Engineering, Eastern Merit Award for Excellence in Education, Distinguished Leadership Award, Golden General Secretary Award, etc. Examples of his publications include-“" Mathematical Application of Simplex Numerical Method in the Allocation of Water in Aboine River Basin of Nigeria", European International Journal of Science and Technology, United Kingdom, Vol. 2 No 5, Pp. 173 - 190", "Development of Model Equations for the Allocation of Water Resources in Anambra Imo River Basin Development Authority of Nigeria, European 
International Journal of Applied Science and Technology, Kent, United Kingdom". He is currently the Chairman of International Conference in Engineering to be hosted by the Faculty of Engineering Imo State University, Owerri, Nigeria. His areas of interest in research include Optimization of Water Resources Engineering Systems, Modelling of Engineering Systems, Numerical Applications in Water Resources Development and Environmental Engineering. His e-mail address is engrlawobi@yahoo.com. 